\title{
Avaliação de sete protocolos para obtenção de plasma rico em plaquetas na espécie equina
}

\author{
Evaluation of seven platelet-rich plasma processing protocols in the equine species
}

\author{
Roberta Carneiro da Fontoura Pereira ${ }^{\mathrm{I}^{*}}$ Gian Vitor Freitas Zacarias ${ }^{\mathrm{II}}$ Camila Cantarelli ${ }^{\mathrm{II}}$ \\ Marcos Matoso Burgo Corrêa ${ }^{I}$ Gabriele Biavaschi da Silva ${ }^{I}$ Anna Laethicia Trindade Barbosa \\ Karin Erica Brass ${ }^{\mathrm{III}}$ Flávio Desessards De La Côrte ${ }^{\mathrm{II}}$
}

RESUMO

O presente estudo teve por objetivo avaliar a capacidade de concentração plaquetária e sua correlação com os niveis do fator de crescimento $T G F-B_{l}$, a presença de leucócitos e de hemácias nos diferentes protocolos utilizados na obtenção do plasma rico em plaquetas (PRP) de equinos, através do método manual. Dez equinos, sadios, com idade média de 7 anos ( $\pm 2,39)$, pesando em média $500 \mathrm{~kg}( \pm 67,1)$ foram utilizados neste estudo. Os protocolos testados variaram na velocidade e no tempo nas duas centrifugações. As variáveis analisadas nas amostras de PRP foram: concentração de plaquetas, presença de leucócitos e hemácias, e niveis de TGF- $\beta_{1}$ quantificados pelo teste ELISA. Os protocolos testados não diferiram na capacidade de concentração de plaquetas e nos níveis de TGF- $\beta_{\text {. }}$. Entretanto, houve diferença significava entre o protocolo I e os demais por este apresentar maior número de hemácias e leucócitos nas amostras de PRP, sendo por esse motivo considerado um protocolo inadequado para processamento do volume de sangue utilizado. Os demais protocolos podem ser utilizados para obtenção de PRP terapêutico em equinos.

Palavras-chave: $P R P$, equino, centrifugação, $T G F-B_{1}$.

\section{ABSTRACT}

PRP is plasma that contains a high numbers of platelets and growth factors in a small volume. The aim of this study was to evaluate seven different protocols to obtain PRP by the manual method according to their capacity to concentrate platelets, leukocyte and erythrocyte contamination and correlation between platelet count and TGF- $\beta_{1}$ growth factor levels in PRP samples. Ten healthy horses with a mean age of 7 years ( \pm 2.39$)$, weighing on average $500 \mathrm{~kg}( \pm 67.1)$ were used in this study. The protocols tested varied according to the speed and time used at the two centrifugations. PRP samples were analyzed regarding platelet concentration, leukocyte and erythrocyte contamination and TGF- $\beta_{1}$ levels quantified by ELISA. No significant differences among protocols were observed regarding the ability to concentrate platelets and TGF- $\beta_{I}$. However, protocol I showed significantly higher erythrocyte and leukocyte counts in PRP samples than the other protocols, reason why it was considered inadequate for the volume of blood processed in this experiment. The remaining protocols are suitable for extracting $P R P$.

Key words: PRP, horse, centrifugation, $T G F-\beta_{I}$.

\section{INTRODUÇÃO}

As plaquetas são pequenos fragmentos citoplasmáticos, anucleados, de forma discoide encontrados na corrente sanguínea que se originam a partir dos megacariócitos presentes na medula óssea (HANDIN et al., 1995). Esses fragmentos além de participarem do processo de hemostasia também atuam na reparação de feridas e na formação de um novo epitélio. A concentração de plaquetas no sangue total dos equinos pode variar entre $100.000 \mathrm{e}$ 350.000 plaquetas $\mu \mathrm{L}^{-1}$ que permanecem viáveis por aproximadamente 10 dias na circulação sanguínea (SCHALM et al., 1975).

A obtenção do plasma rico em plaquetas (PRP) pelo método manual é uma técnica simples e de baixo custo que consiste da coleta de sangue autógeno em tubos contendo citrato de sódio ou em bolsas de sangue contendo citrato/fosfato/dextrose/

IPrograma de Pós-graduação em Medicina Veterinária, Universidade Federal de Santa Maria (UFSM), Av. Roraima, 1000, prédio 97, Camobi, 97105-900, Santa Maria, RS, Brasil. E-mail: betacfp@hotmail.com.br.*Autor para correspondência.

IICurso em Medicina Veterinária, UFSM, Santa Maria, RS, Brasil.

IIIDepartamento de Grandes Animais (DGA), Centro de Ciências Rurais (CCR), UFSM, Santa Maria, RS, Brasil. 
adenina como anticoagulante. No processamento, pode-se realizar uma ou duas centrifugações do sangue total (VENDRAMIN et al., 2006; CARMONA, 2006), quando o produto final resulta em um pequeno volume de plasma com elevado número de plaquetas e fatores de crescimento (VENDRAMIN et al., 2006), sendo considerado uma opção útil no tratamento de muitas enfermidades (MAIA \& SOUZA, 2009).

Os fatores de crescimento (FC) provenientes dos $\alpha$-grânulos plaquetários estimulam a quimiotaxia, proliferação e diferenciação celular, síntese de colágeno, neovascularização e deposição de matriz extracelular (EVERTS et al., 2006). Na literatura são descritos pelo menos sete FC derivados dos $\alpha$-grânulos plaquetários: $\mathrm{FC}$ de transformação beta (TGF- $\beta$ ), FC derivado de plaquetas (PDGF), FC semelhante à insulina I (IGF-I), FC fibroblástico (FGF), FC epidermal (EGF), FC vascular endotelial (VEGF) e FC do tecido conjuntivo (CTGF) (CARMONA, 2006; MAIA, 2008; BARBOSA et al., 2008). Devido a essas propriedades, o PRP se tornou um produto com grande potencial na integração de enxertos, sejam eles ósseos, cutâneos, cartilaginosos ou de gordura, bem como estimulante na cicatrização de feridas (VENDRAMIN et al., 2009).

O PRP tem sido bastante estudado na odontologia humana, sendo aplicado, principalmente, em pequenos enxertos ósseos realizados na região alveolar de implantes dentários e em cirurgias periodontais e maxilofaciais (MARX et al., 1998; ANITUA, 1999; MARX, 2004). Na medicina humana, o uso do PRP tem apresentado efeitos positivos em cirurgias plásticas (VEDRAMIN et al., 2006), ortopédicas (MISHRA \& PAVELKO, 2006), e também no tratamento de osteoartrite (SANCHEZ et al., 2012). Entretanto, na medicina veterinária equina, o uso do PRP é mais recente com sua utilização descrita no tratamento de feridas (CARTER et al., 2003), tendinites e desmites (MAIA, 2008; SUTTER et al., 2008), osteoartrite (CARMONA et al., 2007), e na cicatrização de fraturas (CARMONA \& LOPEZ, 2011).

$\mathrm{Na}$ medicina humana e veterinária, diversos protocolos para a obtenção de PRP foram propostos com o objetivo de concentrar um maior número de plaquetas viáveis em um volume mínimo de plasma (MARX, 2004; VENDRAMIN et al, 2006; CARMONA, 2006; MAIA, 2008; VENDRAMIN et al 2009). Em virtude disso, o objetivo do presente estudo foi avaliar sete protocolos de obtenção de PRP quanto à capacidade de concentração plaquetária, presença de hemácias e leucócitos, e correlação entre a concentração de plaquetas e a de FC TGF- $\beta_{1}$ nas amostras de PRP obtidas.

\section{MATERIAL E MÉTODOS}

\section{Seleção dos animais}

Dez cavalos adultos (cinco machos e cinco fêmeas), com idade média de 7 anos $( \pm 2,39)$, pesando em média $500 \mathrm{~kg}( \pm 67,1)$, clinicamente sadios, cujos parâmetros hematológicos e bioquímicos se encontravam dentro do intervalo de referência foram utilizados neste estudo. Só foram incluídos animais que apresentaram um número de plaquetas no sangue total superior a 100.000 plaquetas $\mu \mathrm{L}^{-1}$. Durante o experimento os animais foram mantidos em baias individuais, com alimentação a base de alfafa, ração comercial e água ad libitum.

\section{Coleta de sangue}

Foram coletadas duas bolsas de sangue de 450ml (CDPA-1) contendo citrato/fosfato/dextrose/ adenina como anticoagulante, através da venopunção com agulha 16-G, de cada um dos dez animais do grupo experimental.

\section{Processamento das amostras}

Para a avaliação de cada protocolo a ser testado, foram utilizados $100 \mathrm{ml}$ de sangue acondicionados, assepticamente, em três tubos de polipropileno do tipo Falcon $(50 \mathrm{ml})$, sendo que, em um tubo, foram depositados $30 \mathrm{ml} \mathrm{e}$, nos dois restantes, $35 \mathrm{ml}$ de sangue sendo que essa divisão foi feita para adequar à centrifuga do modelo ALC 4237 centrífuge. Os tubos Falcon com o sangue foram centrifugados uma primeira vez para separar o plasma da zona de névoa (camada flogística que contém os leucócitos) e hemácias. O plasma sobrenadante contendo as plaquetas foi transferido para um segundo tubo Falcon e novamente centrifugado, conforme o protocolo testado. Após essa segunda centrifugação o plasma sobrenadante foi descartado sendo conservados apenas $10 \mathrm{ml}$ de PRP, equivalentes a $10 \%$ do volume do sangue total inicial. As amostras de PRP foram acondicionadas em tubos eppendorf. Toda a manipulação das amostras foi realizada em uma capela de fluxo laminar.

\section{Protocolos utilizados}

Os protocolos (P) utilizados no processamento do sangue para a obtenção de PRP variaram quanto à velocidade e tempo de centrifugação como segue: PI centrifugação a $120 \mathrm{~g}$ e $240 \mathrm{~g}$, ambas por 5 minutos (CARMONA, 2006); PII centrifugação a $120 \mathrm{~g}$ e $240 \mathrm{~g}$ durante 10 minutos (min) cada (CARMONA, 2006 modificado); PIII centrifugação a $300 \mathrm{~g}$ e $640 \mathrm{~g}$ por $10 \mathrm{~min}$ (VENDRAMIN, 2006);

Ciência Rural, v.43, n.6, jun, 2013. 
PIV centrifugação a $400 \mathrm{~g}$ e $800 \mathrm{~g}$ por $10 \mathrm{~min}$ (VENDRAMIN, 2009); PV centrifugação a $224 \mathrm{~g}$ e $440 \mathrm{~g}$ por $10 \mathrm{~min}$; PVI centrifugação a $113 \mathrm{~g}$ e $652 \mathrm{~g}$ por 10 e $5 \mathrm{~min}$ (BARBOSA, 2012 - informe verbal), respectivamente; PVII centrifugação a $120 \mathrm{~g}$ e $473 \mathrm{~g}$ por 5 min (MAIA, 2008) (Tabela1). Os protocolos PI, PIII, PIV e PVII foram adaptados dos protocolos originais (CARMONA, 2006; VENDRAMIN et al., 2006; VENDRAMIN et al., 2009; MAIA, 2008) já que neste experimento modificaram-se alguma variáveis, como: volume de sangue, tubos para coleta de sangue, tipo de anticoagulante e porcentagem de descarte do plasma sobrenadante.

\section{Avaliação laboratorial das amostras}

Amostras de $2 \mathrm{ml}$ de sangue total e de PRP obtido a partir de cada protocolo foram enviadas em tubos eppendorf ao laboratório para determinação do número de plaquetas, hemácias e leucócitos. A contagem das plaquetas foi realizada pelo método manual. Para tanto cada amostra de sangue e PRP foi diluída e homogeneizada em líquido de Brecher com oxalato de amônia a 1\%. A contagem foi realizada em câmara de Neubauer, utilizando microscópio óptico binocular com aumento de 400x. A contagem das hemácias e leucócitos foi realizada com um contador hematológico semiautomático por impedância BCVet-2800 Mindray ${ }^{\circledR}$ (STOCKHAM et al., 2002). A concentração de plaquetas ([plaquetas]) foi determinada dividindo o número de plaquetas no PRP pelo número de plaquetas no sangue total.

Amostras obtidas a partir de cada protocolo foram estocadas em tubos eppendorf a $-80^{\circ} \mathrm{C}$ para dosagem do FC TGF- $\beta_{1}$ usando o kit Quantikine ELISA Human TGF- $\beta_{1}$.

\section{Análise estatística}

Os resultados obtidos foram analisados usando ANOVA e a comparação múltipla entre as

Tabela 1- Força e tempo de centrifugação dos protocolos usados para obtenção de PRP.

\begin{tabular}{lcccc}
\hline \multirow{2}{*}{ Protocolos } & \multicolumn{2}{c}{--Primeira centrifugação--- ---Segunda centrifugação--- } \\
& Força (g) & Tempo (min) & Força (g) & Tempo (min) \\
\hline I & 120 & 5 & 240 & 5 \\
II & 120 & 10 & 240 & 10 \\
III & 300 & 10 & 640 & 10 \\
IV & 400 & 10 & 800 & 10 \\
V & 224 & 10 & 440 & 10 \\
VI & 113 & 10 & 652 & 5 \\
VII & 120 & 5 & 473 & 5 \\
\hline
\end{tabular}

médias das concentrações plaquetária foi realizada pelo teste de Turkey. A análise de correlação foi usada para testar a relação entre a contagem de plaquetas e TGF- $\beta_{1}$. Todas as análises foram realizadas usando o software Graphpad 5.0 com nível de significância em $\mathrm{P}<0,05$. Os dados são apresentados como média \pm erro padrão da média.

\section{RESULTADOS}

Plaquetas - A concentração de plaquetas obtida utilizando sete diferentes protocolos é apresentada na figura 1 . Não foi observada diferença na capacidade de concentrar plaquetas entre os sete protocolos usados na obtenção de PRP neste estudo (Figura 1A) $(\mathrm{P}>0,05)$. Todos os protocolos testados permitiram concentrar plaquetas em média quatro vezes acima do número inicial de plaquetas presente no sangue total. Em ordem decrescente os protocolos que resultaram na maior concentração média de plaquetas foram: PVI $(5,4)$; PIV $(4,8)=$ PV $(4,8)$; PII (4,7); PIII (4,6); PVII (4,5); PI (4,1).

Leucócitos - Considerando a presença de leucócitos no PRP (Figura 1B), o PI, seguido dos protocolos PVII, PII, PVI, PV, PIV, PIII, foi o protocolo que apresentou maior concentração desse parâmetro nas amostras analisadas $(\mathrm{P}<0,05)$.

Hemácias - A presença de hemácias (Figura 1C) nas amostras de PRP foi semelhante aos leucócitos na ordem decrescente de contaminação (PI; PVII; PII; PVI; PV; PIV = PIII), não houve contaminação com hemácias nas amostras obtidas a partir dos PIII e PIV $(\mathrm{P}<0,05)$.

TGF- $\beta_{1}$ - Não foi observada diferença entre os sete protocolos quanto à presença do FC TGF- $\beta_{1}$ nas amostras analisadas. Também não houve correlação entre a concentração plaquetária, contagem de plaquetas e a concentração de TGF- $\mathrm{B}_{1}$ nos sete protocolos testados $(\mathrm{P}<0,05)$. As médias de TGF- $\beta_{1}$ nos sete protocolos na ordem decrescente foram: $14053 \pm 5862 \mathrm{pg} \mathrm{ml}^{-1}(\mathrm{PI}), 12397 \pm 1517 \mathrm{pg} \mathrm{ml}^{-1}$ (PVII), $10518 \pm 2515 \mathrm{pg} \mathrm{ml}^{-1}$ (PVI), $10004 \pm 2440 \mathrm{pg}$ $\mathrm{ml}^{-1}(\mathrm{PV}), 8796 \pm 2294 \mathrm{pg} \mathrm{ml}^{-1}$ (PIV), $7634 \pm 1218 \mathrm{pg}$ $\mathrm{ml}^{-1}$ (PII) e $7198 \pm 2996 \mathrm{pg} \mathrm{ml}^{-1}$ (PIII) $(\mathrm{P}<0,05)$.

\section{DISCUSSÃO}

Neste estudo, foram usados apenas protocolos que utilizam duas centrifugações porque protocolos que incluem somente uma centrifugação não produzem PRP, mas sim uma mistura de plasma pobre em plaquetas (PPP) e PRP, o que resulta em baixa concentração total de plaquetas (MARX, 2001). 


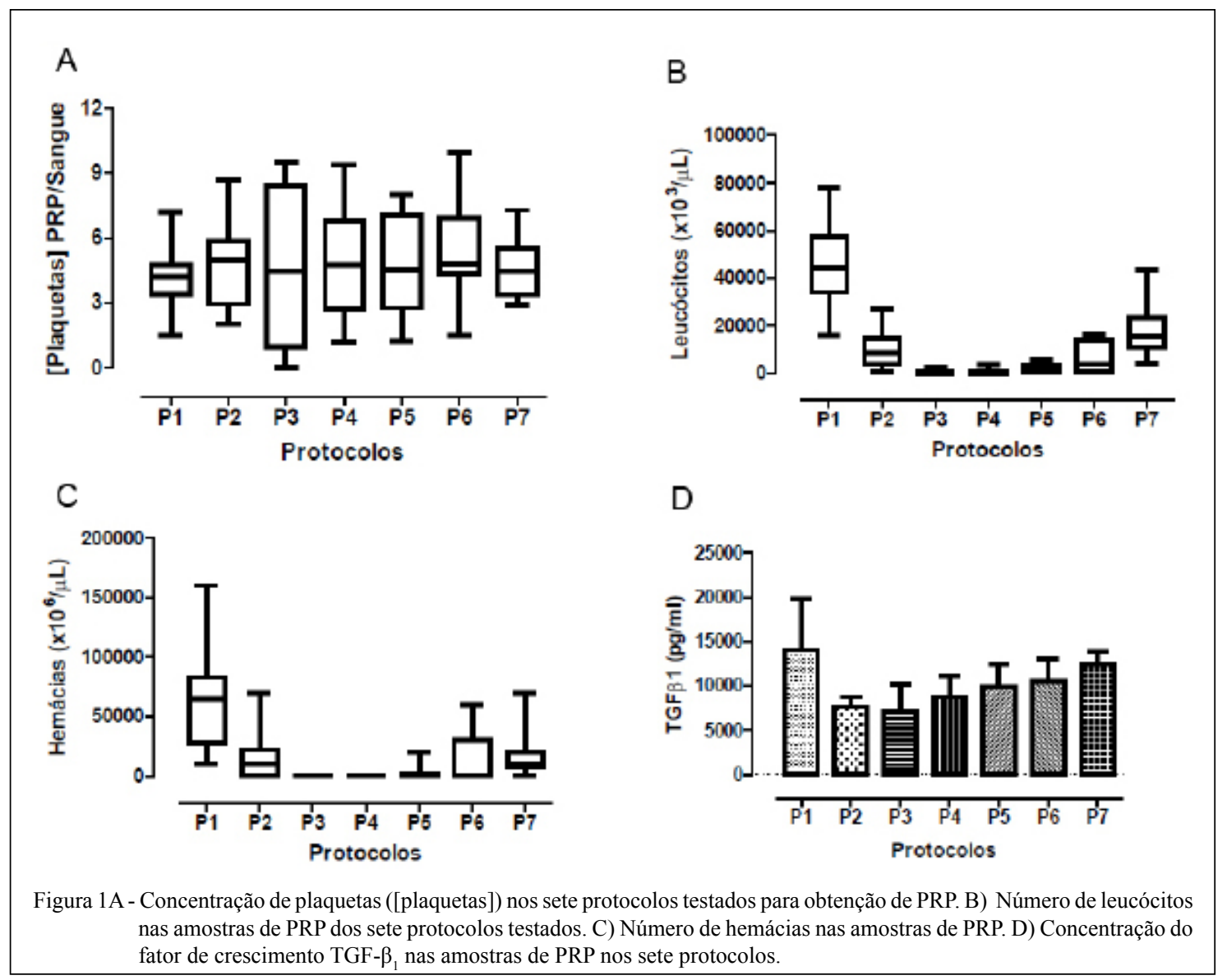

A maior força $g$ e maior tempo na primeira e/ou segunda centrifugação utilizada nos protocolos PIV, PV e PVI resultaram em maior concentração plaquetária com médias de 4,8, 4,8 e 5,4 , respectivamente. A quantidade de plaquetas necessária para auxiliar nos processos cicatriciais ainda é incerta (MC LELLAN \& PLEVIN, 2011). A recomendação atual é que a concentração de plaquetas viáveis no PRP seja de 3 a 5 vezes superior à presente no sangue total (MARX, 2004; SMITH et al., 2006). Isso é observado em todos os protocolos testados neste experimento, em que as médias da concentração de plaquetas se mantiveram neste intervalo.

A média de concentração das plaquetas de 4,6 no PIII foi semelhante ao observado por VENDRAMIN et al., (2006). Quando a média de concentração de plaquetas no PRP obtida com o PI $(4,1)$ é comparada com a de Carmona (2006) e a do PVII $(4,5)$ com a de MAIA (2008), observa-se que as médias obtidas neste trabalho foram superiores às descritas pelos autores citados em seus respectivos estudos, utilizando mesmo protocolo, porém com volume de sangue diferente. No PIV, a concentração de plaquetas no PRP foi de 4,8 apresentando resultado inferior ao observado pelo autor desse protocolo, utilizando menor volume de sangue total (VENDRAMIN et al., 2009).

Os protocolos utilizados (quanto ao tempo e à força g) foram os mesmos que no experimento dos autores CARMONA (2006) e MAIA (2008), porém a metodologia utilizada foi diferente em relação ao volume de sangue, o tipo de centrífuga, o tipo de anticoagulante presente no sistema de coleta e o profissional treinado. MESSORA et al., (2009) acredita que esses fatores possam interferir também na concentração final de plaquetas no PRP.

Através do método manual de obtenção do PRPa média do número de plaquetas nos sete protocolos foi de $618.757 \pm 91.630$ plaquetas $\mathrm{ml}^{-1}$, número maior de plaquetas que o observado por CARMONA (2006) (250.000 plaquetas $\mathrm{ml}^{-1}$ ) utilizando método manual, e CARTER et al. (2003) (490.000 plaquetas $\mathrm{ml}^{-1}$ ), utilizando o método semiautomático, e menor que Sutter et al. (2004) (855.000 plaquetas $\mathrm{ml}^{-1}$ ), utilizando o método semi-automático de obtenção de PRP.

Considerando a contaminação das amostras de PRP com leucócitos (Figura 1B) e

Ciência Rural, v.43, n.6, jun, 2013. 
hemácias (Figura 1C), os protocolos PI, PVII e PII foram os que apresentaram maior índice desses constituintes nos ensaios $(\mathrm{P}<0,05)$. Isso é atribuido à menor força $\mathrm{g}$ e ao menor tempo de centrifugação usados nesses protocolos e, possivelmente, ao maior volume de sangue utilizado neste experimento do que o usado pelos autores desses protocolos.

MARX \& GARG (1999) relatam que a presença de leucócitos no PRP lhe confere resistência natural a processos infecciosos e/ou alérgicos. MCCARREL \& FORTIER (2009) não consideram a presença de leucócitos no PRP um fator positivo e sugerem uma relação entre a presença de leucócitos no PRP, aumento do catabolismo e diminuição da síntese de matriz extracelular nos tecidos. Isso pode ser importante quando se considera o uso intraarticular do PRP. CARMONA (2006) recomenda minimizar o número de leucócitos no PRP quando se deseja utilizá-lo em articulações. Mais ainda, parece haver uma correlação positiva entre as células brancas do sangue e o fator de necrose tumoral e a interleucina 1 (MC CARREL \& FORTIER, 2009). Portanto, o método para a obtenção de PRP mais adequado seria aquele que também resulta na menor presença de leucócitos para maximizar os benefícios das plaquetas.

Neste estudo não foram observadas diferenças significativas entre os protocolos quanto à capacidade de concentração de plaquetas e os níveis de TGF- $\beta_{1}$ fato este também observado por VENDRÚSCULO et al. (2011). O PI e o PVII foram os protocolos que apresentaram maior quantidade de TGF- $\beta_{1}$ nas amostras. Esses protocolos também apresentaram a maior presença de leucócitos. Segundo WEIBRICH et al., (2003) existem outras células além das plaquetas, como os leucócitos, que têm a capacidade de liberar fatores de crescimento. A média de TGF- $\beta_{1}$ nas amostras obtidas a partir dos sete protocolos foi de $10085 \pm 2492 \mathrm{pg} \mathrm{ml}^{-1}$, superior à descrita por CARTER et al. (2003) (7480 pg $\mathrm{ml}^{-1}$ ), mas inferior às encontradas por SUTTER et al. (2004) (23600 $\mathrm{pg} \mathrm{ml}^{-1}$ ) e CARMONA (2006) (12515 $\left.\mathrm{pg} \mathrm{ml}^{-1}\right)$.

Embora o PRP seja, sem dúvida alguma, uma alternativa terapêutica promissora na medicina equina, ainda há muitas lacunas relativas ao seu uso que devem ser preenchidas. Para o uso seguro e eficaz do PRP em cavalos é necessário, entre outros, determinar a frequência ideal de administração, bem como o volume a ser utilizado, a necessidade de ativação das plaquetas em algumas ou em todas as terapias e o momento em que o uso desta terapia é mais eficiente.

\section{CONCLUSÃO}

Apesar de não terem sido observadas diferenças entre os protocolos testados, recomenda-se o uso dos protocolos PIV, PV e PVI para obtenção de PRP, pois esses foram os protocolos que apresentaram maiores médias de concentrações plaquetárias, níveis favoráveis de TGF-B ${ }_{1}$ e menor presença de hemácias e leucócitos.

\section{COMITÊ DE ÉTICA E BIOSSEGURANÇA}

Este trabalho foi aprovado pelo Comitê de Ética em Experimentação Animal da Universidade Federal de Santa Maria (UFSM) com o número do parecer 045/2011.

\section{INFORME VERBAL}

Protocolo da tese em desenvolvimento "Célulastronco mononucleares associadas ao plasma rico em plaquetas na consolidação da falha óssea no cão" da autoria de Anna Laeticia da Trindade Barbosa na Universidade Federal de Santa Maria.

\section{REFERÊNCIAS}

ANITUA, E. Plasma rich in growth factors: preliminary results of use in the preparations of future sites for implants. International Journal Oral Maxillofacial Implants, v.14, p.529-535, 1999. Disponível em: <http://www.ncbi.nlm.nih.gov/pubmed/10453668>. Acesso em 10 de outubro de 2011. doi: 10453668.

BARBOSA, A.L.T. et al. Plasma rico em plaquetas para a reparação de falhas ósseas em cães. Ciência Rural, v.38, n.5, p. 13351340, 2008. Disponível em: <http://www.scielo.br/pdf/cr/v38n5/ a21v38n5.pdf $>$. Acesso em 6 de novembro de 2011. doi:10.1590/ S0103-84782008000500021.

CARMONA, J.U. et al . Use of autologous platelet concentrates for the treatment of musculoskeletal injuries in the horse. 2006. 91f. Tese de Doutorado em Medicina Veterinária. Universidade Autonoma de Barcelona. Disponível em: <http://www.tdx.cat/ bitstream/handle/10803/5732/jucr1de1.pdf?sequence=1>. Acesso em 19 de novembro de 2011.

CARMONA, J.U. et al. Autologous platelet concentrates as a treatment of horses with osteoarthiritis: a preliminary pilot clinical study. Journal of Equine Veterinary Science, v.27, n.4, p.167170, 2007. Disponível em: <http://www.sciencedirect.com/science/ article/pii/S0737080607000846>. Acesso em 19 de novembro de 2011. doi: $10.1016 /$ j.jevs.2007.02.007.

CARMONA, J.U.; LÓPEZ, C. Autologous platelet concentrates as a treatment for shoulder injury in a horse. Journal of Equine Veterinary Science, v. 31, n. 9, p. 1-5, 2011. Disponível em: $<$ http:// www.j-evs.com/article/S0737-0806(11)00100-6/abstract>. Acesso em 19 de dezembro de 2011. doi:10.1016/j.jevs.2011.03.008.

CARTER, C.A. et al. Platelet rich plasma gel promotes differentiation and regeneration during equine wound healing. Experimental and Molecular Pathology, v. 74, p. 244-255, 2003. Disponível em: <http://www.sciencedirect.com/science/article/ pii/S0014480003000170>. Acesso em 29 de novembro de 2011. doi:10.1016/S0014-4800(03)00017-0. 
EVERTS, P.A.M. et al. Platelet-rich plasma and platelet gel: a review. Journal of Extracorporeal Technology, Bloomsburg, v.38, n.2 p.174-187, 2006. Disponível em: <http://www.ncbi.nlm. nih.gov/pubmed/16921694>. Acesso em 11 de janeiro de 2011 doi:16921694.

HANDIN, R.I., et al. Blood: principles, practice of hematology. Philadelphia: J. B. Linppincott, 1995.

MAIA L. Plasma rico em plaquetas no tratamento de tendinite em eqüinos: avaliação clínica, ultrasonográfica e histopatológica. 2008. 78f. Dissertação de Mestrado em Medicina Veterinária UniversidadeFederal de Viçosa. Disponívelem: $<$ http://www.scielo. br/scielo.php?pid=S0100-736X2009000300009\&script $=$ sci arttext $>$. Acesso em 10 de novembro de 2011. doi:10.1590/S0100$736 \times 2009000300009$.

MAIA, L.; SOUZA, M.V. Componentes ricos em plaquetas na reparação de afecções tendo-ligamentosas e osteoarticulares em animais. Ciência Rural, Santa Maria, v.39, n.4, p. 1267-1274, 2009. Disponível em: <http://www.scielo.br/scielo.php?pid=S0103$84782009000400050 \&$ script $=$ sci_abstract\&tlng $=\mathrm{pt}>$. Acesso em 24 de outubro de 2011. doi:10.1590/S0103-84782009005000040.

MARX, R.E.; GARG, A.K. Bone graft physiology with use of platelet-rich plasma and hiperbaric oxygen. In: The sinus bone graft. Colorado: Quintessense, p.183-189, 1999.

MARX, R.E. Platelet-rich plasma (PRP): What is PRP and what is not PRP? Implant Dentristry, v.10, n.4, p.225-228, 2001. Disponível em: <http://www.dierenartshoegaerts.be/nl/therapie/ injecties/documents/prpwhatisprpandwhatisnot.pdf $>$. Acesso em 20 de outubro de 2011

MARX, R.E. Platelet-rich plasma: Evidence to support its use. Journal Oral Maxillofacial Surgery, n. 62, p.489-496, 2004. Disponível em: <http://www.joms.org/article/S0278 $2391 \% 2803 \% 2901272-2 /$ abstract>. Acesso em 22 de outubro de 2011. doi:10.1016/j.joms.2003.12.003.

MC CARREL, T \& FORTIER, L.A. Temporal growth factor release from platelet-rich plasma, thehalose lyophilized platelets, and bone marrow aspirate and their effect on tendon and ligament gene expression. Journal Orthophaedic Research, v.27, p.10331042, 2009. Disponível em: <http://onlinelibrary.wiley.com/ doi/10.1002/jor.20853/abstract $>$. Acesso em 20 de janeiro de 2012. doi: $10.1002 /$ jor. 20853 .

MC LELLAN, J \& PLEVIN, S. Evidence- based clinical question. Does it matter which platelet-rich plasma we use? Equine Veterinary Education, v.23, n.2, p.101-104, 2011. Disponível em: $\quad<$ http://onlinelibrary.wiley.com/doi/10.1111/j.20423292.2010.00185.x/pdf $>$. Acesso em 20 de janeiro de 2012. doi: 10.1111/j.2042-3292.2010.00185.x.

MISHRA, A; PAVELKO, T. Treatment of chronic elbow tendinosis with buffered platelet-rich plasma. American Journal Sports of Medicine, v. 10, n.10, p.1-5, 2006. Disponível em: <http://ajs. sagepub.com/content/34/11/1774.full.pdf + html $>$. Acesso em 23 de janeiro de 2012. doi: 10.1177/0363546506288850.

SÁNCHEZ, M. et al. Ultrasound-guided platelet -rich plasma injections for the treatment of osteoarthritis of the hip.
Rheumatology, v.51, n.1, p.144-150, 2012. Disponível em: $<$ http://rheumatology.oxfordjournals.org/content/51/1/144.full. pdf + html $>$. Acesso em 3 de fevereiro de 2012. doi:10.1093/ rheumatology/ker303.

SCHALM, O.W et al. Normal values in blood morphology with comments of species characteristics in response to disease. In: Veterinary Hematology. $3^{\mathrm{a}}$ ed., Philadelphia: Lea \& Febiger, Cap. 3, p. 82-218, 1975.

SMITH, J.J. et al. Anabolic effects of acellular bone marrow, platelet rich plasma, and serum on equine suspensory ligament fibroblasts in vitro. Veterinary and Comparative Orthopaedics and Traumatology, v. 19, p. 43-47, 2006. Disponível em: <http:// www.vetcell.com/assets/Research-papers/Anabolic-effects.pdf $>$. Acesso em 22 de dezembro de 2011

SUTTER, W.W. et al. Comparison of hematologic values and transforming growth factor-beta and insulin-like growth factor concentrations in platelet concentrates obtained by use of buffy coat and apheresis methods from equine blood. American Journal Veterinary Research, Schaumburg, v.65, n.7, p.924-930. 2004. Disponível em: <http://avmajournals.avma.org/doi/abs/10.2460/ ajvr.2004.65.924>. Acesso em 18 de novembro de 2011. doi: 10.2460/ajvr.2004.65.924

SUTTER, W.W. et al. Intralesional injection of platelet-rich plasma for mid-body suspensory ligament desmitis in Standardbred race horses. Journal American Veterinary Medical Association, v. 232,n.10, p.1515-1520, 2008. Disponível em: $<$ http://avmajournals. avma.org/doi/abs/10.2460/javma.232.10.1515>. Acesso em $10 \mathrm{de}$ dezembro de 2011. doi: 10.2460/javma.232.10.1515.

STOCKHAM, S.L.; SCOTT, M, A. Fundamental of Veterinary Clinical Pathology. Editora Iowa State, 2002. Cap. 2., p. 31 - 58.

VENDRAMIN, F.S. et al. Plasma rico em plaquetas e fatores de crescimento: técnica de obtenção e utilização em cirurgia plástica. Revista do Colégio Brasileiro de Cirurgiões, v.33, n.1, p. 24-28, 2006. Disponível em: <http://www.scielo.br/ scielo.php?pid $=$ S0100-69912006000100007\& script $=$ sci arttext>. Acesso em 08 de outubro de 2011. doi:10.1590/S010069912006000100007

VENDRAMIN, F.S. et. al. Método de obtenção do gel de plasma rico em plaquetas autólogo. Revista Brasileira de Cirurgia Plástica, v.24, n.2, p. 212-218, 2009. Disponível em: <http://www. rbcp.org.br/detalhe_artigo.asp?id=471>. Acesso em 08 de outubro de 2011 .

VENDRUSCULO, C.P. et al. Avaliação da eficácia de diferentes protocolos de preparo do plasma rico em plaquetas para uso em medicina equina. In: XII Conferência anual da ABRAVEQ, 2011, Campinas, São Paulo. Anais... Abraveq- Associação Brasileira dos Médicos Veterinários de Equídeos, 2011, v.35, p.239, p. 189.

WEIBRICH, G. et al. Comparison of platelet, leukocyte, and growth factor levels in point-of-care platelet-enriched plasma, prepared using a modified Curasan kit, with preparations received from a local blood bank. Clinical Oral Implants Research, p.357-362, 2003. Disponível em: <http://onlinelibrary.wiley.com/ doi/10.1034/j.1600-0501.2003.00810.x/abstract>. Acesso em 27 de janeiro de 2011. doi: 10.1034/j.1600-0501.2003.00810.x. 